\title{
Article
}

\section{Clinical Differences in c-Myc Expression in Early-Stage Gastric Neoplasia: A Retrospective Study Based on the WHO Classification}

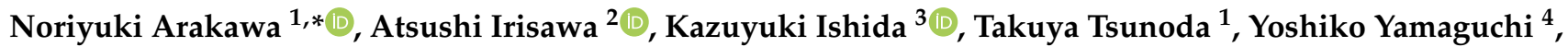 \\ Goro Shibukawa ${ }^{5}$, Makoto Eizuka ${ }^{6}$, Shunzo Tokioka ${ }^{1}$ and Hiroto Wakabayashi ${ }^{1}$
}

check for

updates

Citation: Arakawa, N.; Irisawa, A.;

Ishida, K.; Tsunoda, T.; Yamaguchi, Y.;

Shibukawa, G.; Eizuka, M.; Tokioka,

S.; Wakabayashi, H. Clinical

Differences in c-Myc Expression in

Early-Stage Gastric Neoplasia: A

Retrospective Study Based on the

WHO Classification. J. Clin. Med.

2022, 11, 544. https://doi.org/

$10.3390 / j \mathrm{~cm} 11030544$

Academic Editor: Ugo Grossi

Received: 7 December 2021

Accepted: 20 January 2022

Published: 21 January 2022

Publisher's Note: MDPI stays neutral with regard to jurisdictional claims in published maps and institutional affiliations.

Copyright: (C) 2022 by the authors. Licensee MDPI, Basel, Switzerland. This article is an open access article distributed under the terms and conditions of the Creative Commons Attribution (CC BY) license (https:/ / creativecommons.org/licenses/by/ $4.0 /)$.
1 Department of Gastroenterology, Takeda General Hospital, Aizuwakamatsu 965-8585, Japan; tsunotaku@takeda.or.jp (T.T.); shunzo.tokioka.1103@gmail.com (S.T.); wakaba@takeda.or.jp (H.W.)

2 Department of Gastroenterology, Dokkyo Medical University School of Medicine, Mibu 321-0293, Japan; irisawa@dokkyomed.ac.jp

3 Department of Pathology, Dokkyo Medical University School of Medicine, Mibu 321-0293, Japan; ishida-k@dokkyomed.ac.jp

4 Department of Pathology, Takeda General Hospital, Aizuwakamatsu 965-8585, Japan; yyamaguchi@takeda.or.jp

5 Department of Gastroenterology, Aizu Medical Center, Fukushima Medical University, Aizuwakamatsu 969-3492, Japan; goro4649@aol.com

6 Department of Molecular Diagnostic Pathology, Iwate Medical University School of Medicine, Iwate 028-3694, Japan; m10_makoeizuka@yahoo.co.jp

* Correspondence: imu_nori0111@yahoo.co.jp; Tel.: +81-242-27-5511

\begin{abstract}
Myc is an oncogene that is dysregulated in various cancers. Early gastric neoplasia with c-Myc expression has been reported as a more malignant lesion. This study clarifies the differences in c-Myc expression in early gastric neoplasia based on the WHO classification. Samples from 100 patients with differentiated-type early gastric neoplasia, who underwent endoscopic submucosal dissection between March 2020 and January 2021, were stained for c-Myc. One hundred lesions were classified as low-grade dysplasia, high-grade dysplasia, or intramucosal adenocarcinoma. The staining intensity and extent were scored. A hierarchical cluster analysis for a clinicopathological analysis among the groups, the chi-square test, Bonferroni correction, and residual analysis were performed. Subgroup one and two consisted of 39 patients; while subgroup three consisted of 22. Significant differences among various characteristics were observed between these subgroups. The frequency of low-grade dysplasia was significantly higher, while that of high-grade dysplasia was significantly lower in subgroup three. The frequency of intramucosal adenocarcinoma was significantly higher in subgroup one. The c-Myc positivity rate was significantly higher in subgroup one compared with that in subgroup three. c-Myc expression distinctly differed in early gastric neoplasia. c-Myc-negative low-grade dysplasia may be separately categorized from c-Myc-positive low-grade dysplasia, high-grade dysplasia, and intramucosal adenocarcinoma.
\end{abstract}

Keywords: gastric cancer; c-Myc; genetic linkage analysis

\section{Introduction}

The use of a genetic analysis to clarify the molecular pathogenesis of gastric cancer has greatly increased in recent years [1]. In Europe and the United States, gastric cancer is diagnosed based on the WHO classification. The intramucosal invasive neoplasia is treated by a mucosectomy or gastrectomy due to the metastatic potential of lesions invading the lamina propria [2]. In Japan, not only an intramucosal adenocarcinoma (IMA), but also low-grade dysplasia (LGD) and high-grade dysplasia (HGD) are targeted for resection. By analyzing the copy number alterations (CNAs) of early-stage gastric cancer, the authors identify several genes that may be related to the early stages of cancer. Among them, a gain 
in c-Myc (8q24.21) is a genetic abnormality that occurs in the early stage of the disease and may be a driver gene [3]. The CNA analysis of 84 cases of gastric intramucosal epithelial tumors showed that the frequency of $8 \mathrm{q}$ gain was increased in HGD and IMA rather than in LGD [4]. It is suggested that the amplification level of c-Myc differs depending on the nuclear and structural atypia. In addition, the gain of a gene has been reported to correlate with an increased protein expression [5].

$\mathrm{c}-\mathrm{Myc}$, an oncogene that is dysregulated in various cancers, is involved in carcinogenesis and cancer progression. This gene has also been associated with a variety of biological phenomena, including the promotion of disordered cell growth, neoangiogenesis, metastasis, anaerobic metabolism, and genomic instability [6].

Considering the results of the genetic analysis reported previously, lesions with c-Myc expression in early gastric neoplasia are likely malignant. However, there have been no reports discussing c-Myc expression with a focus on the WHO classification. This study was conducted to clarify the differences in c-Myc expression in early gastric neoplasia based on the WHO classification.

\section{Materials and Methods}

\subsection{Study Design}

This was a retrospective study conducted in a single center and approved by the Clinical Research Ethics Committee of Takeda General Hospital and registered with the University Hospital Medical Information Network (registration number UMIN000044040). Written informed consent was obtained from each patient included in the study, which was performed in accordance with the Declaration of Helsinki. The primary endpoint of the study was hierarchical cluster analysis based on the scores obtained by c-Myc staining to clarify the characteristics of each group. The secondary endpoints of the study were the c-Myc expression rates in early gastric neoplasia based on the WHO classification.

\subsubsection{Patients}

We evaluated 107 patients who underwent endoscopic submucosal dissection at the Department of Gastroenterology, Takeda General Hospital, between March 2020 and January 2021, and were diagnosed with differentiated-type early gastric neoplasia based on histopathological examination. A total of 100 cases was included, excluding mixed tissue types (cases in which a component of the secondary tissue type accounted for more than $10 \%$ of the total, or cases in which the component of the secondary tissue type was small but included poorly differentiated cancer).

\subsubsection{Immunohistochemistry}

Lesions removed by endoscopic submucosal dissection were fixed in $10 \%$ buffered formalin, and the specimens were prepared by total segmentation. The pathological diagnosis was determined following hematoxylin and eosin staining according to the gastric cancer treatment protocol, and the WHO classification was determined [2,7]. One hundred lesions were classified as LGD (Figure 1), HGD (Figure 2), or IMA (Figure 3) using the WHO classification criteria. The WHO classification for intramucosal lesions was used for cases of submucosal invasive cancer. Immunostaining was performed on representative sections following speculum examination. Immunostaining was performed using an automated immunostainer (Histostainer, Nichirei, Tokyo, Japan) and the anti-cMyc antibody (clone EP121, Nichirei). Staining was evaluated by scoring the intensity and extent of staining (as described below) [8,9]. c-Myc expression was evaluated for nuclear rather than cytoplasmic staining. The staining intensity was classified as negative ( 0 points), weak (1 point), moderate ( 2 points), or strong ( 3 points). The staining field was defined as follows: less than $10 \%$ ( 0 points), $11-25 \%$ ( 1 point), $26-50 \%$ ( 2 points), and $>50 \%$ ( 3 points). The obtained values were multiplied and scores of $>4$ points were considered as positive, whereas scores of $<4$ points were considered as negative. The stained area was measured 
using the ImageJ software (v.1.52a, National Institutes of Health, Bethesda, MD, USA) [10]. An example of the stain interpretation is shown in Figure 4.

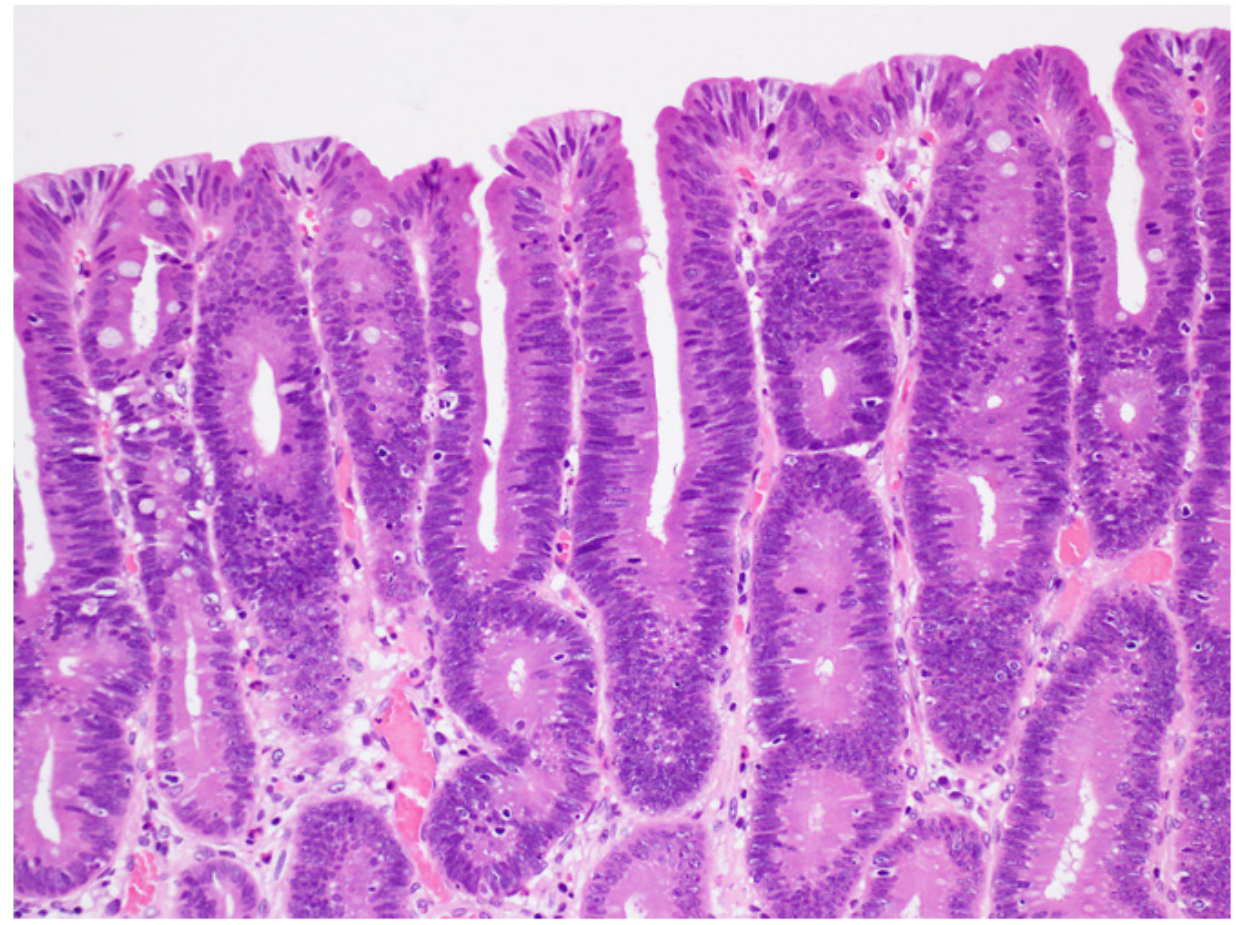

Figure 1. Low-grade dysplasia. Glands are slightly crowed with a regular shape and size. The nuclei are cigar shaped and basally oriented.

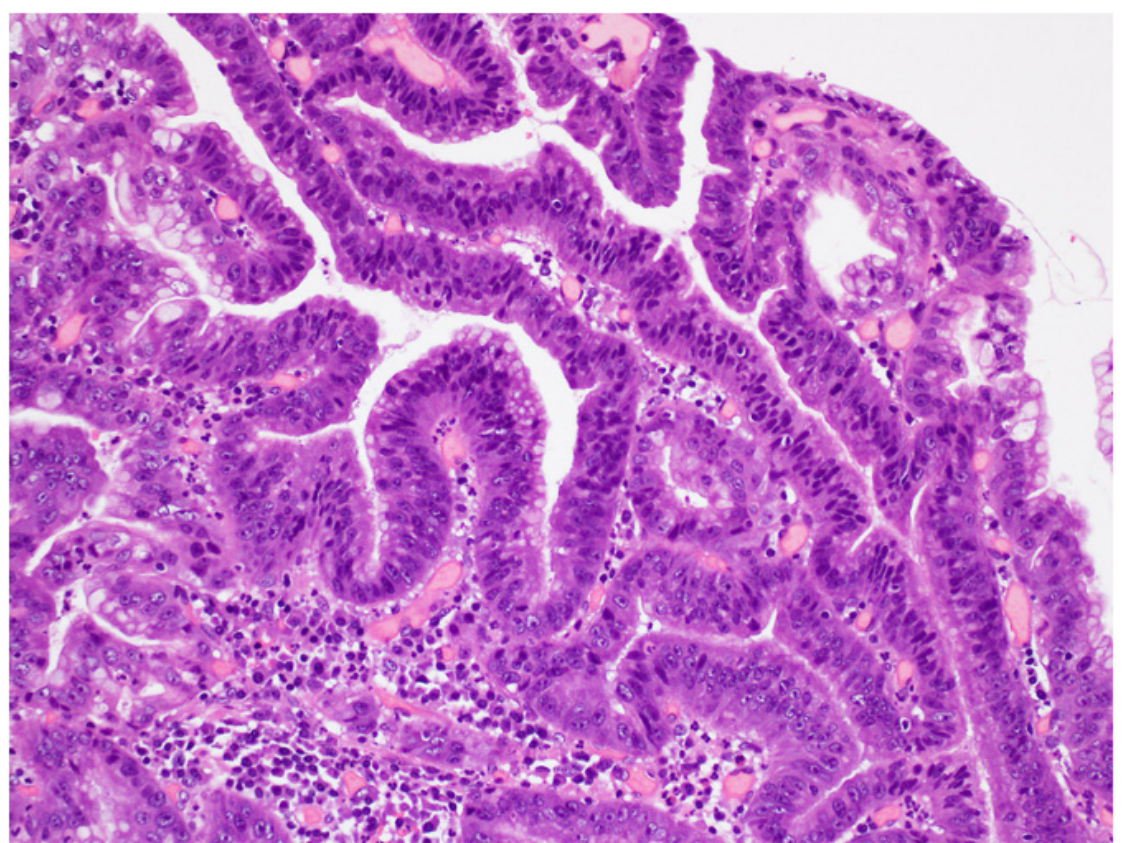

Figure 2. High-grade dysplasia. Glands have a variable size and shape. The nuclei are irregular in shape and size. 


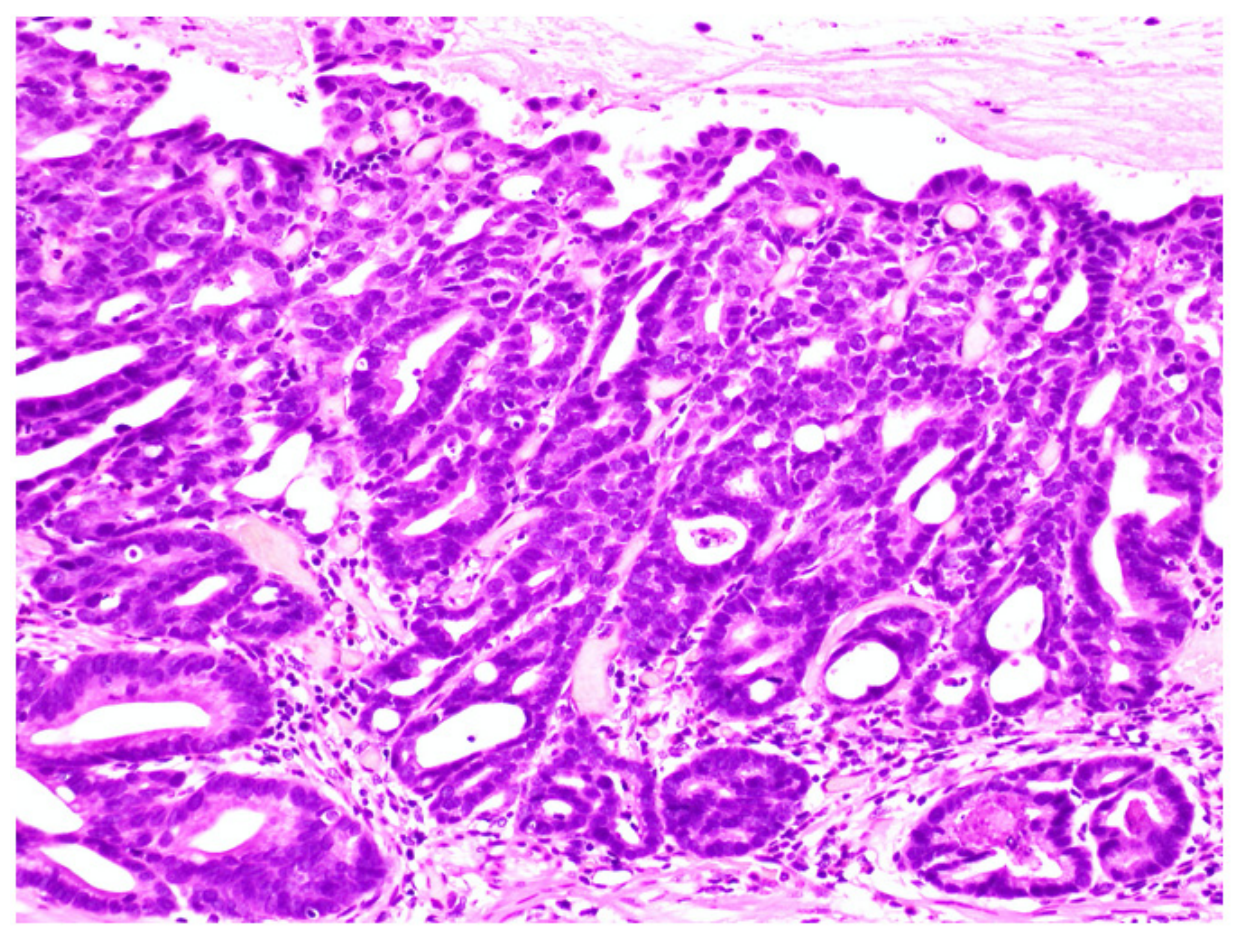

Figure 3. Intramucosal adenocarcinoma. Glands have a complex architecture with irregular branching and glandular anastomosis. Invasion into the lamina propria with no evident desmoplastic reaction.
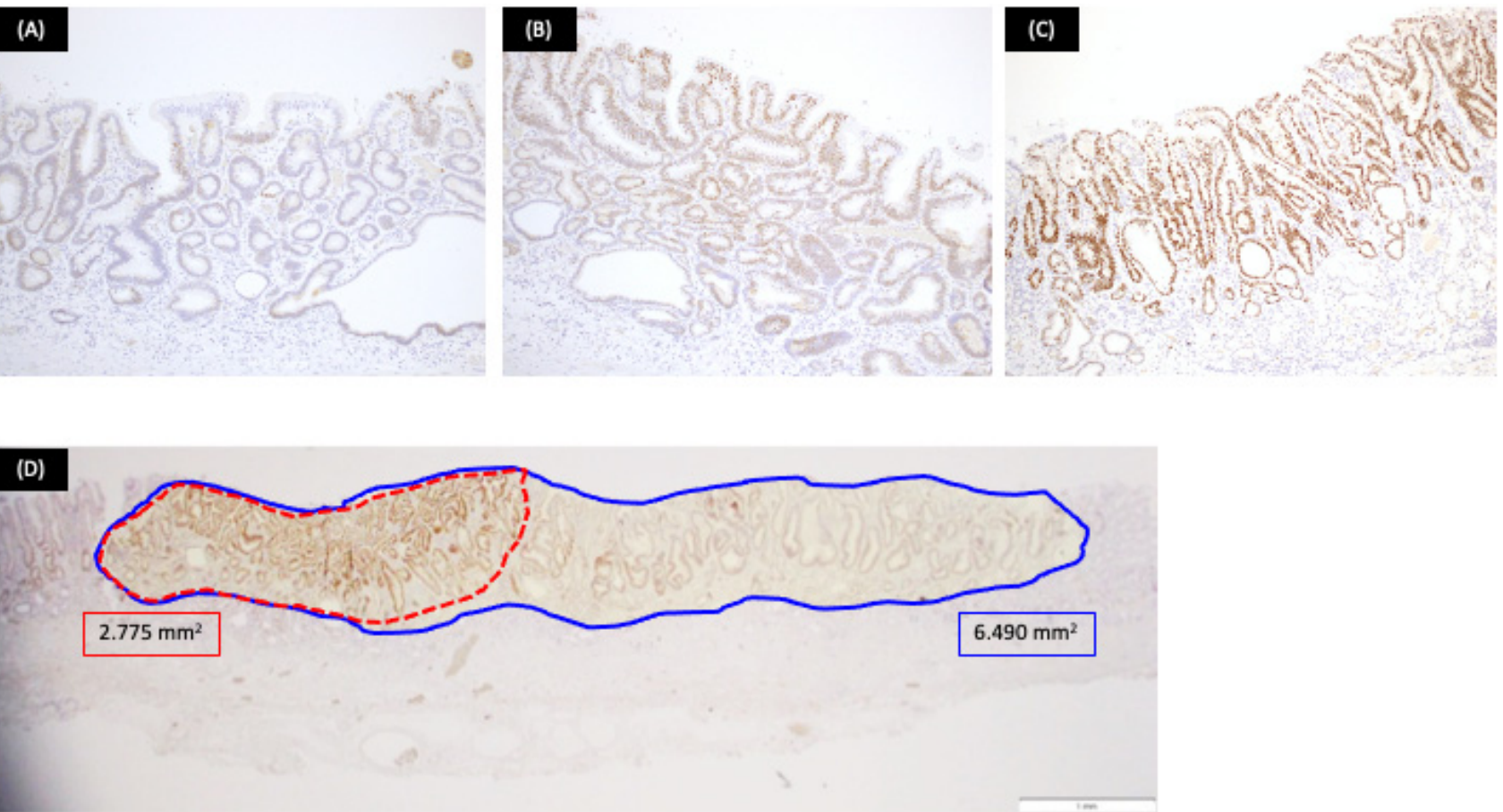

Figure 4. Example of stain interpretation. (A): Staining intensity: 1 point (c-Myc; $\times 40)$; (B): staining intensity: 2 points $(\mathrm{c}-\mathrm{Myc} ; \times 40)$; (C): staining intensity: 3 points $(\mathrm{c}-\mathrm{Myc} ; \times 40) ;(\mathbf{D})$ : stained area was measured using the ImageJ software. Red and blue frames show c-Myc positive and gastric neoplasia areas, respectively.

\subsubsection{Statistical Analysis}

Hierarchical cluster analysis was performed using the obtained data [11]. The chisquare test, Bonferroni correction, and residual analysis were used for the statistical analyses 
of the three subgroups (StatMate-III software, Atom, Tokyo, Japan). $p<0.05$ was considered as the threshold for a statistically significant difference.

\section{Results}

\subsection{Clinical Pathological Evaluation}

The clinicopathological results of the 100 cases of early gastric neoplasia evaluated based on the WHO classification are shown in Table 1. In terms of the invasion depth, the frequency of T1a was higher in LGD (100\%) and that of T1b was higher in IMA (25\%) $(p<0.01)$ among the groups. In terms of the gross morphology, the elevated type was more frequent in LGD $(70.8 \%)$, the mixed type was more frequent in HGD $(11.1 \%)$, and the depressed type was more frequent in IMA $(87.5 \%)(p<0.01)$. The c-Myc positivity rate was higher in HGD (94.4\%) and IMA (100\%) compared with that in LGD (41.7\%) $(p<0.01)$.

Table 1. Clinicopathological findings of early gastric neoplasia patients.

\begin{tabular}{|c|c|c|c|c|}
\hline & LGD & HGD & IMA & $p$ Value \\
\hline Total & 48 & 36 & 16 & \\
\hline Age (range) & $78(57-87)$ & $79.5(62-94)$ & $78.5(64-92)$ & N.S \\
\hline Sex (Man/Woman) & $30 / 18$ & $22 / 14$ & $12 / 4$ & N.S \\
\hline \multicolumn{5}{|l|}{ Locus } \\
\hline Upper & 13 & 10 & 4 & N.S \\
\hline Middle & 22 & 8 & 6 & N.S \\
\hline Lower & 13 & 18 & 6 & N.S \\
\hline \multicolumn{5}{|l|}{ Depth (\%) } \\
\hline T1a & $48(100)$ & $32(88.9)$ & $12(75)$ & $<0.01$, N.S, $<0.01$ \\
\hline T1b & $0(0)$ & $4(11.1)$ & $4(25)$ & $<0.01$, N.S,$<0.01$ \\
\hline \multicolumn{5}{|l|}{ Macroscopy (\%) } \\
\hline elevated & $34(70.8)$ & $18(50)$ & $2(12.5)$ & $<0.01$, N.S,$<0.01$ \\
\hline depressed & $14(29.2)$ & $14(38.9)$ & $14(87.5)$ & $<0.05$, N.S,$<0.01$ \\
\hline Mixed & $0(0)$ & $4(11.1)$ & $0(0)$ & $<0.05,<0.01$, N.S \\
\hline \multicolumn{5}{|c|}{ c-Myc expression (\%) } \\
\hline positive & $20(41.7)$ & $34(94.4)$ & $16(100)$ & $<0.01,<0.01,<0.01$ \\
\hline negative & $28(58.3)$ & $2(5.6)$ & $0(0)$ & $<0.01,<0.01,<0.01$ \\
\hline
\end{tabular}

Low-grade dysplasia; LGD, high-grade dysplasia; HGD, intramucosal adenocarcinoma; IMA, not significant; N.S.

\subsection{Hierarchical Cluster Analysis}

A hierarchical cluster analysis was performed based on the staining intensity, staining range, and score (Figure 5). Subgroups one, two, and three consisted of 39, 39, and 22 patients, respectively. Clinicopathological analyses were performed among the subgroups (Table 2).

Table 2. Clinicopathological findings based on Hierarchical cluster analysis.

\begin{tabular}{lcccc}
\hline & Subgroup1 & Subgroup2 & Subgroup3 & $p$ Value \\
\hline Total & 39 & 39 & 22 & \\
\hline Age (range) & $78(63-93)$ & $78(57-94)$ & $78(68-88)$ & N.S \\
\hline Sex (Man/Woman) & $29 / 10$ & $23 / 16$ & $12 / 10$ & N.S \\
\hline Locus (\%) & & & $2(9.1)$ & $<0.05$, N.S, $<0.05$ \\
Upper & $16(41)$ & $10(25.6)$ & $12(54.5)$ & $<0.01$, N.S, $<0.01$ \\
Middle & $8(20.5)$ & $16(41.0)$ & $8(36.4)$ & N.S, N.S, N.S \\
Lower & $15(38.5)$ & $13(33.3)$ & & \\
\hline Depth (\%) & & & & \\
T1a & $33(84.6)$ & $37(94.9)$ & $22(100)$ & $<0.05$, N.S, N.S \\
T1b & $6(15.4)$ & $2(5.1)$ & $0(0)$ & $<0.05$, N.S, N.S \\
\hline
\end{tabular}


Table 2. Cont.

\begin{tabular}{lcccc}
\hline & Subgroup1 & Subgroup2 & Subgroup3 & $p$ Value \\
\hline $\begin{array}{l}\text { Macroscopy (\%) } \\
\text { elevated } \\
\text { depressed }\end{array}$ & $14(35.9)$ & $22(56.4)$ & $18(81.8)$ & $<0.01, \mathrm{~N} . \mathrm{S},<0.01$ \\
Mixed & $22(56.4)$ & $16(41.0)$ & $4(18.2)$ & $<0.05, \mathrm{~N} . \mathrm{S},<0.05$ \\
\hline WHO (\%) & $3(7.7)$ & $1(2.6)$ & $0(0)$ & N.S, N.S, N.S \\
$\quad$ IMA & $14(35.9)$ & $2(5.1)$ & $0(0)$ & $<0.01,<0.05,<0.05$ \\
HGD & $17(43.6)$ & $17(43.6)$ & $2(9.1)$ & N.S, N.S, $<0.01$ \\
LGD & $8(20.5)$ & $20(51.3)$ & $20(90.9)$ & $<0.01$, N.S, $<0.01$ \\
\hline $\begin{array}{l}\text { c-Myc expression (\%) } \\
\text { positive } \\
\text { negative }\end{array}$ & $39(100)$ & $31(79.5)$ & $0(0)$ & $<0.01, \mathrm{~N} . \mathrm{S},<0.01$ \\
\hline
\end{tabular}
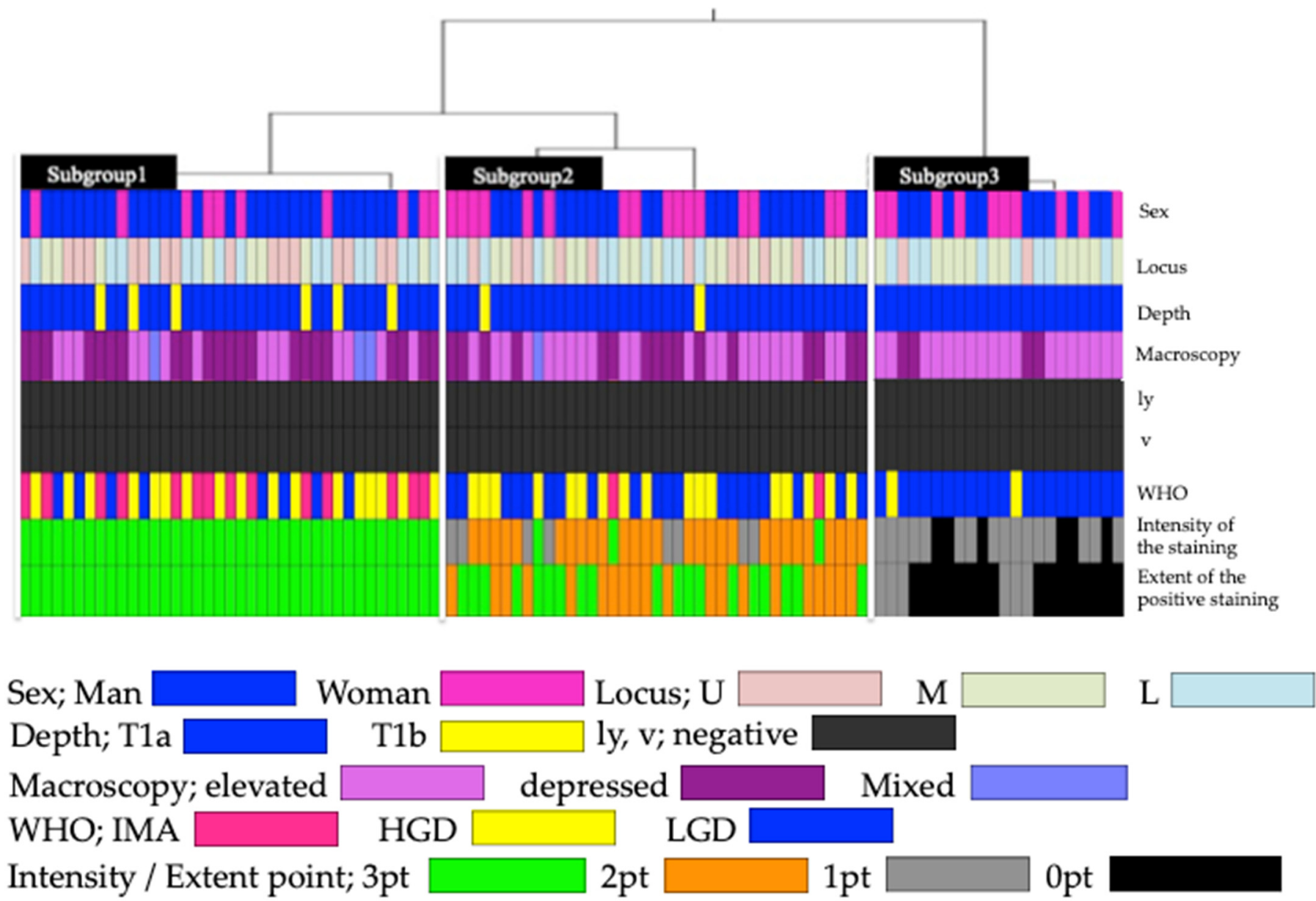

Figure 5. Hierarchical cluster analysis based on c-Myc expression. U: upper; M: middle; L: lower; ly: lymphatic invasion; v: venous invasion; LGD: low-grade dysplasia; HGD: high-grade dysplasia; IMA: intramucosal adenocarcinoma.

An origin in the upper part of the body was significantly more frequent in subgroup one $(41 \%)(p<0.05)$, and the origin was proximal to the midline of the body significantly more frequently in subgroup three $(54.5 \%)(p<0.01)$. In terms of the invasion depth, the frequency of T1b was significantly higher in subgroup one $(15.4 \%)(p<0.05)$. In terms of the gross morphology, the elevated type was significantly more frequent in subgroup three $(81.8 \%)(p<0.01)$, and the depressed type was significantly more frequent in subgroup one $(56.4 \%)(p<0.05)$. 
The frequency of LGD was significantly higher in subgroup three $(90.9 \%)$ than in subgroup one $(20.5 \%)$ and subgroup two $(51.3 \%)(p<0.01)$. The frequency of IMA was significantly higher in subgroup one $(35.9 \%)$ than in subgroup two (5.1\%) and subgroup three $(0 \%)(p<0.01)$. The frequency of HGD was significantly lower in subgroup three $(9.1 \%)$ than in subgroup one (43.6\%) and subgroup two (43.6\%).

The c-Myc positivity rate was significantly higher in subgroup one $(100 \%)$ than in subgroup three $(0 \%)(p<0.01)$, while that in subgroup two $(79.5 \%)$ did not differ significantly from that in the other groups.

\section{Discussion}

The molecular pathogenic mechanisms of cancer can be broadly classified into genomic and epigenomic abnormalities [12]. Genomic abnormalities include the loss of heterozygosity, mutations, and CNA. In recent years, many genes that may be key drivers of gastric cancer have been reported. In 2018, Nanki et al. [13] reported that most gastric cancers depend on the growth factor Wnt. Abnormal Wnt signaling induces the nuclear heteroaccumulation of $\beta$-catenin, which in turn induces abnormal cell proliferation via the overexpression of oncogenes, such as cyclin D1 and c-Myc. As a result of the CNA analysis of early gastric cancer, a gain of c-Myc was frequently observed, which may be closely related to abnormalities in Wnt signaling [3,4]. The current study was conducted to clarify the biological importance of c-Myc expression in early gastric neoplasia based on the WHO classification.

The cluster analysis was performed based on the c-Myc staining results. Each cluster showed independent clinicopathological features, which could be classified into three patterns in terms of c-Myc expression: subgroup one, characterized by a high c-Myc expression, high frequency of IMA, and depressed gross morphology; subgroup three, characterized by a low c-Myc expression, and most cases involving LGD and an elevated gross morphology; subgroup two, exhibiting intermediate characteristics between subgroups one and three, with no significant differences. Notably, the positive rate of c-Myc expression was $100 \%$ for IMA, $94.4 \%$ for HGD, and 41.7\% for LGD. In early gastric neoplasia, c-Myc expression was correlated with nuclear and structural atypia. The incidence of immunostaining in early gastric cancer was reported as 18.1-100\% [14-20]. However, these studies included both differentiated and poorly differentiated adenocarcinomas and were not evaluated using the WHO classification.

Nakayama et al. [21] reported highly interesting data on c-Myc expression. They used laser microdissection to extract DNA from intramucosal carcinoma, submucosal invasive carcinoma, and advanced carcinoma, and performed a CNA analysis by array comparative genomic hybridization. Myc loss and TP53 gain are defined as dormant patterns, whereas Myc gain and/or TP53 loss are defined as aggressive patterns. The results of the genealogical analysis suggested that differentiated adenocarcinomas with dormant patterns rarely develop into advanced cancer. In addition, some intramucosal carcinomas showed an aggressive pattern. This disease state may have undergone an epigenetic change (methylation) that was, subsequently, corrected. The c-Myc expression rate of LGD in this study was 41.7\%. LGD with c-Myc expression is referred to as aggressive LGD, and LGD without c-Myc expression is referred to as dormant LGD. Aggressive LGD may readily progress to HGD and IMA.

In gastric cancer, c-Myc expression is an indicator of malignancy and poor prognosis [14], but is not necessarily high in patients with advanced gastric cancer. The level of the c-Myc messenger RNA expression has been reported as higher in early gastric cancer than in advanced gastric cancer [22]. c-Myc has been shown to further increase the expression level of genes with some level of expression and to alter the characteristics of cancer cells $[23,24]$. Therefore, the expression of c-Myc is thought to be a genetic abnormality in the early stages of carcinogenesis.

Presently, there are no reports, including basic research studies, on the potential of c-Myc as a therapeutic target in advanced gastric cancer. This is because c-Myc is a nuclear 
molecule and has no target-binding site for small molecules, making it unsuitable for drug design [25]. In contrast, BET inhibitors (JQ1, ARV-825), which indirectly inhibit c-Myc, have been reported in hematopoietic tumors [26,27]. Further studies are required to determine whether BET inhibitors can be used to treat solid tumors, including gastric cancer.

\section{Conclusions}

We observed a clear clinicopathological difference in c-Myc expression in early gastric neoplasia based on the WHO classification. These results suggested that the dormant LGD tumor group belongs to a different category than aggressive LGD, HGD, and IMA. The expression of c-Myc is thought to be a key element in the early stages of carcinogenesis. When biopsies are taken by upper endoscopy and proliferative LGD is diagnosed, cMyc staining can be used as a supplementary tool to determine whether the tumor is aggressive. However, gastric cancer is considered to have a strong heterogeneity and should be carefully evaluated.

Author Contributions: N.A. and A.I. collected the data and wrote the paper. A.I., K.I., Y.Y., G.S., M.E., S.T. and H.W. provided clinical advice, Resources, T.T. and G.S. All authors have read and agreed to the published version of the manuscript.

Funding: This research received no external funding.

Institutional Review Board Statement: The study was conducted according to the guidelines of the Declaration of Helsinki and approved by the Clinical Research Ethics Committee of Takeda General Hospital and registered with the University Hospital Medical Information Network (registration number UMIN000044040).

Informed Consent Statement: Informed consent was obtained from all subjects involved in the study.

Data Availability Statement: The data that support the findings of this study are available from the corresponding author, N.A., upon reasonable request.

Acknowledgments: We thank members of the Department of Pathology, Takeda General Hospital, for their support.

Conflicts of Interest: The authors declare no conflict of interest.

\section{References}

1. Cancer Genome Atlas Research Network. Comprehensive Molecular Characterization of Gastric Adenocarcinoma. Nature 2014, 513, 202-209. [CrossRef]

2. The WHO Classification Tumours Editorial Board. WHO Classification of Tumours: Digestive System Tumours, 5th ed.; IARC Press: Lyon, France, 2019.

3. Arakawa, N.; Sugai, T.; Habano, W.; Eizuka, M.; Sugimoto, R.; Akasaka, R.; Toya, Y.; Yamamoto, E.; Koeda, K.; Sasaki, A.; et al. Genome-wide analysis of DNA copy number alterations in early and advanced gastric cancers. Mol. Carcinog. 2017, 56, 527-537. [CrossRef]

4. Sugai, T.; Eizuka, M.; Arakawa, N.; Osakabe, M.; Habano, W.; Fujita, Y.; Yamamoto, E.; Yamano, H.; Endoh, M.; Matsumoto, T.; et al. Molecular profiling and comprehensive genome-wide analysis of somatic copy number alterations in gastric intramucosal neoplasias based on microsatellite status. Gastric Cancer 2018, 21, 765-775. [CrossRef]

5. Dang, C.V. MYC on the Path to Cancer. Cell 2012, 149, 22-35. [CrossRef]

6. $\quad$ Eilers, M.; Eisenman, R.N. Myc's Broad Reach. Genes Dev. 2008, 22, 2755-2766. [CrossRef]

7. Japanese Gastric Cancer Association. Japanese Classification of Gastric Carcinoma, 15th ed.; Kanehara Shuppan: Tokyo, Japan, 2017. (In Japanese)

8. Chiurillo, M.A. Role of the Wnt/ $\beta$-catenin pathway in gastric cancer: An in-depth literature review. World J. Exp. Med. 2015, 5, 84-102. [CrossRef]

9. Oliveira, L.A.; Oshima, C.T.F.; Soffner, P.A.; Silva, M.S.; Lins, R.R.; Malinverni, A.C.M.; Waisberg, J. The Canonical Wnt Pathway in Gastric Carcinoma. Arq. Bras. Cir. Dig. 2019, 32, e1414. [CrossRef]

10. Schneider, C.A.; Rasband, W.S.; Eliceiri, K.W. NIH Image to ImageJ: 25 Years of image analysis. Nat. Methods 2012, 9, 671-675. [CrossRef]

11. Kanda, Y. Investigation of the Freely Available Easy-to-Use Software 'EZR' for Medical Statistics. Bone Marrow Transplant. 2013, 48, 452-458. [CrossRef]

12. Lengauer, C.; Kinzler, K.W.; Vogelstein, B. Genetic instability in colorectal cancers. Nature 1997, 386, 623-627. [CrossRef] 
13. Nanki, K.; Toshimitsu, K.; Takano, A.; Fujii, M.; Shimokawa, M.; Ohta, Y.; Matano, M.; Seino, T.; Nishikori, S.; Ishikawa, K.; et al. Divergent Routes toward Wnt and R-spondin Niche Independency during Human Gastric Carcinogenesis. Cell 2018, 174, 856-869.e17. [CrossRef]

14. Han, S.; Kim, H.Y.; Park, K.; Cho, H.J.; Lee, M.S.; Kim, H.J.; Kim, Y.D. c-Myc expression is related with cell proliferation and associated with poor clinical outcome in human gastric cancer. J. Korean Med. Sci. 1999, 14, 526-530. [CrossRef]

15. Sanz-Ortega, J.; Steinberg, S.M.; Moro, E.; Saez, M.; Lopez, J.A.; Sierra, E.; Sanz-Esponera, J.; Merino, M.J. Comparative study of tumor angiogenesis and immunohistochemistry for p53, c-ErbB2, c-myc and EGFr as prognostic factors in gastric cancer. Histol. Histopathol. 2000, 15, 455-462.

16. Xu, A.-G.; Li, S.-G.; Liu, J.-H.; Gan, A.-H. Function of apoptosis and expression of the proteins Bcl-2, p53 and C-myc in the development of gastric cancer. World J. Gastroenterol. 2001, 7, 403-406. [CrossRef] [PubMed]

17. Ishii, H.H.; Gobé, G.C.; Pan, W.; Yoneyama, J.; Ebihara, Y. Apoptosis and cell proliferation in the development of gastric carcinomas: Associations with c-myc and p53 protein expression. J. Gastroenterol. Hepatol. 2002, 17, 966-972. [CrossRef]

18. Raiol, L.C.C.; Silva, E.C.F.; da Fonseca, D.M.; Leal, M.F.; Guimarães, A.C.; Calcagno, D.Q.; Khayat, A.S.; Assumpção, P.P.; de Arruda Cardoso Smith, M.; Burbano, R.R. Interrelationship between MYC gene numerical aberrations and protein expression in individuals from northern Brazil with early gastric adenocarcinoma. Cancer Genet. Cytogenet. 2008, 181, 31-35. [CrossRef]

19. Calcagno, D.Q.; Freitas, V.M.; Leal, M.F.; De Souza, C.R.T.; Demachki, S.; Montenegro, R.C.; Assumpção, P.P.; Khayat, A.S.; de Smith, M.D.A.C.; dos Santos, A.K.C.R.; et al. MYC, FBXW7 and TP53 copy number variation and expression in Gastric Cancer. BMC Gastroenterol. 2013, 13, 141. [CrossRef]

20. Khaleghian, M.; Jahanzad, I.; Shakoori, A.; Razavi, A.E.; Azimi, C. Association between Amplification and Expression of C-MYC Gene and Clinicopathological Characteristics of Stomach Cancer. Iran. Red Crescent Med. J. 2016, 18, e21221. [CrossRef]

21. Nakayama, T.; Ling, Z.Q.; Mukaisho, K.; Hattori, T.; Sugihara, H. Lineage Analysis of Early and Advanced Tubular Adenocarcinomas of the Stomach: Continuous or Discontinuous? BMC Cancer 2010, 10, 311. [CrossRef]

22. Onoda, N.; Maeda, K.; Chung, Y.S.; Yano, Y.; Matsui-Yuasa, I.; Otani, S.; Sowa, M. Overexpression of c-myc messenger RNA in primary and metastatic lesions of carcinoma of the stomach. J. Am. Coll. Surg. 1996, 182, 55-59.

23. Lin, C.Y.; Lovén, J.; Rahl, P.B.; Paranal, R.M.; Burge, C.B.; Bradner, J.E.; Lee, T.I.; Young, R.A. Transcriptional Amplification in Tumor Cells with Elevated c-Myc. Cell 2012, 151, 56-67. [CrossRef]

24. Nie, Z.; Hu, G.; Wei, G.; Cui, K.; Yamane, A.; Resch, W.; Wang, R.; Green, D.R.; Tessarollo, L.; Casellas, R.; et al. c-Myc Is a Universal Amplifier of Expressed Genes in Lymphocytes and Embryonic Stem Cells. Cell 2012, 151, 68-79. [CrossRef] [PubMed]

25. Whitfield, J.; Beaulieu, M.-E.; Soucek, L. Strategies to Inhibit Myc and Their Clinical Applicability. Front. Cell Dev. Biol. 2017, 5, 10. [CrossRef] [PubMed]

26. Delmore, J.E.; Issa, G.C.; Lemieux, M.E.; Rahl, P.B.; Shi, J.; Jacobs, H.M.; Kastritis, E.; Gilpatrick, T.; Paranal, R.M.; Qi, J.; et al. BET Bromodomain Inhibition as a Therapeutic Strategy to Target c-Myc. Cell 2011, 146, 904-917. [CrossRef]

27. Lu, J.; Qian, Y.; Altieri, M.; Dong, H.; Wang, J.; Raina, K.; Hines, J.; Winkler, J.D.; Crew, A.P.; Coleman, K.; et al. Hijacking the E3 Ubiquitin Ligase Cereblon to Efficiently Target BRD4. Chem. Biol. 2015, 22, 755-763. [CrossRef] 